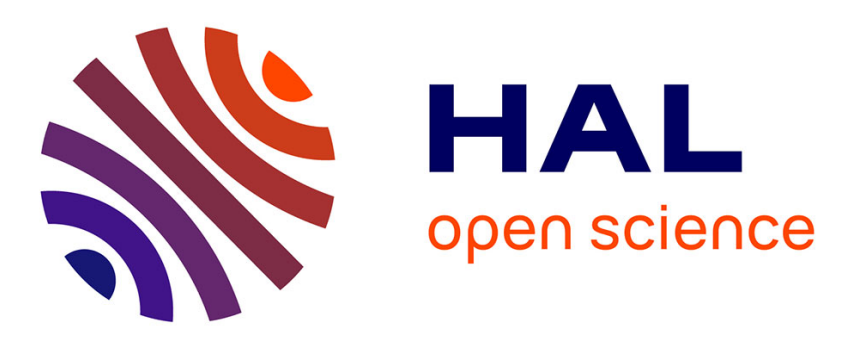

\title{
Transport processes induced by metastable boiling water under Martian surface conditions
}

\author{
Marion Massé, Susan J. Conway, Julien Gargarni, Manish R. Patel, Kelly \\ Pasquon, Alfred Mcewen, Vincent Chevrier, Matt R. Balme, Lujendra Ojha, \\ Sabrina Carpy, et al.
}

\section{To cite this version:}

Marion Massé, Susan J. Conway, Julien Gargarni, Manish R. Patel, Kelly Pasquon, et al.. Transport processes induced by metastable boiling water under Martian surface conditions. Nature, 2016, 9:, pp.425-428. 10.1038/ngeo2706 . hal-01414502

\section{HAL Id: hal-01414502 https://hal.science/hal-01414502}

Submitted on 8 Jan 2021

HAL is a multi-disciplinary open access archive for the deposit and dissemination of scientific research documents, whether they are published or not. The documents may come from teaching and research institutions in France or abroad, or from public or private research centers.
L'archive ouverte pluridisciplinaire HAL, est destinée au dépôt et à la diffusion de documents scientifiques de niveau recherche, publiés ou non, émanant des établissements d'enseignement et de recherche français ou étrangers, des laboratoires publics ou privés. 


\title{
Transport processes resulting from metastable boiling water under Mars surface conditions
}

\author{
M. Massé*a,f, S. J. Conway ${ }^{\mathrm{a}, \mathrm{c}}$, J. Gargani ${ }^{\mathrm{b}}$, M. R. Patel ${ }^{\mathrm{c}}$, K. Pasquon ${ }^{\mathrm{b}}$, A. McEwen ${ }^{\mathrm{d}}$, V.
} Chevrier $^{\mathrm{e}}$, M. R. Balme ${ }^{\mathrm{c}}$, L. Ojha ${ }^{\mathrm{g}}$, S. Carpy ${ }^{\mathrm{a}}$, M. Vincendon ${ }^{\mathrm{f}}$, F. Poulet ${ }^{\mathrm{f}}$, F. Costard ${ }^{\mathrm{b}}$, G. Jouannic $^{\mathrm{h}}$

${ }^{a}$ Laboratoire de Planétologie et Géodynamique, UMR 6112, CNRS, Université de Nantes, 2 chemin de la Houssinière, BP 92205, 44322 Nantes Cedex 3 (France). marion.masse@univ-nantes.fr susan.conway@univ-nantes.fr sabrina.carpy@univ-nantes.fr

${ }^{b}$ Géosciences Paris Sud, UMR 8148, CNRS, Université Paris-Sud XI, Bâtiment 504, Rue du Belvédère, 91405 Orsay Cedex (France) julien.gargani@u-psud.fr kelly.pasquon@u-psud.fr francois.costard@u-psud.fr

${ }^{c}$ Department of Physical Sciences, Open University, Walton Hall, Milton Keynes MK7 6AA (UK) manish.patel@open.ac.uk matt.balme@open.ac.uk

${ }^{d}$ Lunar and Planetary Laboratory, University of Arizona, 1541 E. University Bvd, Tucson, AZ-85721, (USA). mcewen@lpl.arizona.edu

${ }^{e}$ Keck Laboratory for Space and Planetary Simulation, Arkansas Center for Space and Planetary Science, FELD 202, University of Arkansas, Fayetteville, AR 72701, (USA). vchevrie@uark.edu

finstitut d'Astrophysique Spatiale, Université Paris-Sud XI, Bâtiment 121, 91405 Orsay Cedex (France) mathieu.vincendon@ias.u-psud.fr francois.poulet@ias.u-psud.fr

${ }^{g}$ School of Earth and Atmospheric Sciences, Georgia Institute of Technology, 311 First Drive, Atlanta, GA 30332-0340 (USA) luju@gatech.edu 
Liquid water or brine could exist on the martian surface today, albeit transiently and in a metastable state ${ }^{1,2}$. However, the positive identification of liquid water or brine on Mars is hampered by our limited knowledge of how metastable liquids interact with sloping sediments. Here, we address this lacuna through experimental simulations of fluid propagation and sediment transport at martian pressure. These experiments show that boiling of pure water at martian pressure induces grain saltation and wholesale slope destabilization: a hybrid flow mechanism involving both wet and dry processes. This effect is decreased for metastable brines, however they can instead form channels. We find that seeping water and brine have a higher geomorphological impact under martian conditions than under terrestrial conditions. This hybrid flow mechanism could be responsible for martian surface changes originally interpreted as either "dry" or "wet" and extends the suite of processes that could be responsible for currently and recently active features.

Determining whether liquid water or brines are presently active on the surface of Mars is of importance for understanding Mars' hydrologic cycle, the potential for extant life, and potential resources for future explorers. Because surface pressure is frequently below the triple point, liquid water is unstable on Mars today ${ }^{1}$. Chemical and thermodynamic models ${ }^{1,2}$ have, however demonstrated that under certain conditions, metastable liquid water can be transiently present, and salts in solution can depress its freezing point and reduce the evaporation rate $^{3,4}$. Therefore, metastable liquid water and/or brines are viable contenders for explaining present-day active processes observed on Mars ${ }^{\text {e.g.5 }}$. So far, morphological and spectral investigations have not provided unambiguous proof of liquid water flowing at the martian surface, although hydrated salt spectral signatures associated with briny flows have been detected ${ }^{6}$. Process inferences by morphological analysis are often based on analogy with terrestrial landforms formed by fluid-sediment interactions, which implicitly exclude the 
possible effects of metastability. In order to be able to interpret martian flow-like morphologies we need to answer the following fundamental questions: (1) what is the mechanism by which metastable water/brine flows over and through a granular substrate under current martian conditions, and (2) what are the resulting spectroscopic and morphological properties that could be detectable from orbital or rover observations?

To respond to these questions, we have performed a set of laboratory simulation experiments with the view of investigating the specific effect of martian pressure on fluid propagation and sediment transport. The most likely source of liquid brine or water for present-day processes is the melting of seasonal frost or ground ice, and deliquescence ${ }^{\text {e.g.7,8, }}$, which are thought to produce only small amounts of liquid water ${ }^{4,8,9,10,11}$. We simulate this relatively low flow rates by ice melting (propagation of $\sim 30 \mathrm{~cm} / \mathrm{hr}$ consistent with calculations of Kereszturi et al. $\left.{ }^{11}\right)$. A $70 \mathrm{~g}$ block of ice was placed and allowed to melt at the top of a $30^{\circ}$ slope covered with loose fine-grained sand (Supplementary Fig. 1). Two different compositions were used for the frozen block: pure water and a eutectic $\mathrm{MgSO}_{4}$ brine solution $(25 \mathrm{wt} \%)$. We first conducted experiments in a Mars Chamber facility ${ }^{12,13}$ to simulate optimal martian conditions for efficient ice melting ${ }^{1,9,14}: 6.5$ or 9 mbar and $293 \mathrm{~K}$. To understand the effect of reduced martian pressure, the experiments were then repeated at terrestrial conditions (1bar, 293K).

Broad similarities can be observed between the experiments conducted under terrestrial and martian pressure: for all experiments, melting of the frozen block led to the formation of a linear, darker toned, downslope-oriented flowpath (Fig. 1a-d). The dark tone is brought about by the saturation of the regolith ${ }^{15}$. Most of the liquid is transported by downslope intergranular flow, or percolation, with only occasional formation of a surface liquid film (Supplementary videos 1-6). Due to the higher viscosity of dense brines, these flows have shorter and wider flowpaths than those of pure water (Fig. 2a, Supplementary Table 1). Their 
higher viscosity is also responsible for a higher sediment-transport capacity ${ }^{16}$ and they sometimes produce a short channel in the upper part of the flowpath (Fig. 1b, d, Supplementary Table 1). In the case of the briny flows, once the flow has dried, there is crystallization of salts over the flow zone.

Under martian pressure, ice melting produces a metastable liquid which evaporates because it boils ${ }^{16}$. The resulting loss of water leads to a shorter final flowpath compared to the ones formed under terrestrial conditions (Fig. 2a). The metastable state of the water causes (1) the percolation to stop once the frozen block has melted, whereas under terrestrial conditions percolation continues (Fig. 2a), and (2) the propagation-rate to be reduced compared to terrestrial conditions $(100 \mathrm{~cm} / \mathrm{h}$ and $51 \mathrm{~cm} / \mathrm{h}$ for terrestrial and $33 \mathrm{~cm} / \mathrm{h}$ and $19 \mathrm{~cm} / \mathrm{h}$ for martian pressure for water and brine respectively).

Under terrestrial pressure, the morphological impact of percolating water flows is negligible to low (Fig. 2b). The most striking difference between terrestrial and martian pressure experiments is the effect of boiling at martian pressure. Boiling is first apparent at the top of the frozen block when the melting starts (Supplementary Video 1). Liquid then begins to percolate into the sand and boiling occurs most vigorously where and when it reaches the interface between the saturated sand and the atmosphere, because the temperature gradient here is the highest (Fig. $3 \mathrm{~T} 1$, Supplementary Videos 1 and 2). This surface boiling causes sediment saltation - presumably particles being entrained in the vapour escaping the substrate. This process gradually constructs a millimetre-high ridge ahead of the flow front, while percolation continues (Fig. 3 T2). The slope angle of the ridge increases as it grows and when it exceeds the dynamic angle of repose $\left(\sim 30-35^{\circ}\right.$ on Mars and Earth $\left.{ }^{17}\right)$ the ridge collapses, triggering a dry granular flow (Fig. 3 T3) and creating a millimetre-high arcuate trough and remnant ridge (Fig. 3 T4, Supplementary Video 2). The flow progression at martian pressure is thus characterised by repeating, successive phases of percolation and dry 
granular flow, creating a series of ridges and troughs along the flowpath (Fig. 1c,

Supplementary Fig. 2 and Supplementary Video 5). The reduction of pressure from 9mbar to 6.5mbar results in more vigorous boiling (Supplementary Video 3). In this case, despite the loss of water producing a shorter flowpath a similar volume of sediment is mobilised (Fig. 2b).

Similar mechanisms are observed for water and briny flows at martian pressure, but the resulting morphologies differ (Fig. 1c-d). The triple point of brines has a lower temperature and pressure compared to pure water, so they are more stable under martian pressure.

Consequently, although briny flows are still consistently shorter and wider than pure water flows, the difference is smaller under martian pressure. (Fig. 2a, Supplementary Table 1). However, higher stability results in less vigorous boiling, less intense saltation and a lower geomorphological impact compared to pure water (Supplementary Video 5 and 6). A briny flow produces a roughened surface comprising mm-scale arcuate ridges and troughs and sometimes the formation of a short channel (Fig. 1d). For experiments performed at $6.5 \mathrm{mbar}$, the brines are less stable, and in one case we observed explosive ejection of saturated sediment associated with boiling during channel-formation, but without further examples we cannot say if this is typical behavior (Fig. 2f; Supplementary Video 4; Supplementary Fig. 2, experiment 17).

Flowing liquid water or brine have been hypothesised to be responsible for present-day changes observed in recurring slope lineae $\left(\right.$ RSL) ${ }^{7}$ (Fig. 4a), slope streaks ${ }^{18}$ (Fig. 4b), gullies ${ }^{19}$ (Fig. 4c) and polar dune flows ${ }^{20}$ (Fig. 4d). These features occur on steep slopes (20-30 $)$ covered by loose sediment or sand. Due to the unstable state of water, other explanations have been proposed that invoke completely dry processes, or $\mathrm{CO}_{2}$ ice sublimation ${ }^{21,22,23}$. Our experiments are not intended to replicate the morphology of such features, but they do provide 
new insights allowing us to better assess the possible involvement of liquid water/brine in their formation and infer their formation process.

First, our experiments clarify the lack of spectroscopic detection of liquid water or brine associated with these active features ${ }^{6,15}$. The propagation of liquid produced by melting, at a low flow rate, occurs mainly by intergranular percolation; channel-formation only leads to the presence of free surface water for a few seconds. However, the main hydrous absorption bands are only detectable if a liquid film is present ${ }^{15}$ at the spatial and spectral resolution of the martian hyperspectral imaging instruments (OMEGA and CRISM). The spectral signature of intergranular water is thus under the detection threshold of current orbital instruments. Therefore, crystallized salts along the path of a briny flow ${ }^{6}$ are the only potentially identifiable spectroscopic signal of the presence of liquid water flows on the current martian surface, in addition to darkening at all wavelengths.

Second, the resulting morphologies observed during the experiments reveal that, due to its metastable state, a small quantity of liquid water ( $70 \mathrm{~g}$ here) reaching the surface can have a disproportionate geomorphological impact (Fig. 2b). The arcuate ridges and troughs observed in our experiments are too small to distinguish with the highest spatial resolution of orbital imagers $(25 \mathrm{~cm} /$ pixel, HiRISE) and could be only detected in-situ. If we scale our experiments for the effect of martian gravity (see Supplementary text) we find that the ridges are 2.5 times wider. Further, in our experiments, the granular flows induced by the advancing flow-front extend over more than $20 \mathrm{~cm}$ and can be at least twice as large as the saturated zone (Supplementary video 5). Because the ridges are 3 times more voluminous under martian gravity, the granular flows will also be 3 times bigger, possibly achieving detectable sizes. At the landscape-scale we might expect larger liquid-volumes, but from our analysis we do not expect the scale of the morphologies to change only the transported volume. On Mars, the saturated area in front of the lobe can remains "unseen" from orbit because of its smaller size 
and/or because, after complete evaporation of the water, the lobe formed by the granular flow is the only remaining morphology. This process could be playing a role in triggering slope streaks (Fig. 4b), and smooth pale fans (Fig. 4a) and large (20 m wide) slumps ${ }^{24}$ located below some active RSL. Furthermore, this activity is expected to produce the gradual or incremental growth observed for $\mathrm{RSL}^{7,8}$.

Our experiments also point out to fundamental differences between the way in which a stable and an unstable liquid propagates through the sediment. This demonstrates that interpretation of any current activity suspected to be water-driven on Mars, cannot be based solely on terrestrial flow morphologies. Brines are often invoked to explain recent changes on Mars, not only because they have a lower melting point, but also because water is not considered stable enough to produce small-scale, slowly propagating surface morphological changes such as RSL ${ }^{4}$. Not only have we shown that very small amounts of unstable water can produce surface changes, but by demonstrating that brines do not produce a higher morphological impact than pure water (Fig. 2b) whatever the surface pressure is.

This work shows that ice melting on a slope under martian pressure leads to a hybrid transport process involving both wet and dry mechanisms. To date, the interpretation of most martian surface activity has been polarised into either dry or wet processes ${ }^{5}$, and unequivocal evidence for any single process has not yet been presented. Our findings, which demonstrate the hybrid flow-mechanism of metastable fluids, extend the suite of processes that could be responsible for currently and recently active features on Mars like RSL. More generally, we have shown that only small amounts of meltwater are required to transport sediment. Even though seasonal $\mathrm{H}_{2} \mathrm{O}$ deposition is much thinner than that of $\mathrm{CO}_{2}{ }^{25,26}$, our results demonstrate that the contribution of $\mathrm{H}_{2} \mathrm{O}$ frost should not be neglected. A combined process involving both $\mathrm{CO}_{2}$ and $\mathrm{H}_{2} \mathrm{O}$ frost destabilization and melt should be considered. 


\section{Methods:}

\section{Experimental setup.}

For each experiment the frozen block was placed towards the top of a $30^{\circ}$ slope covered with loose sand (Supplementary Fig. 1) and was allowed to melt at a temperature consistent with summer martian conditions ${ }^{9}(293 \mathrm{~K})$. The loose sand was placed on a plastic board, providing an impermeable layer simulating the bedrock or a layer of permafrost. Sand was adhered to the board to increase the roughness preventing basal sliding. A $30^{\circ}$ angle was selected to fit with measured $\mathrm{RSL}^{7}$, polar dune flow ${ }^{20}$ average slopes and slope streak ${ }^{18}$ and gully ${ }^{27}$ proximal slopes. In order to investigate the effect of sand thickness, the board was covered by either $1-2 \mathrm{~mm}$ or $3-4 \mathrm{~mm}$ of fine sand $(200-250 \mu \mathrm{m})$. These sand thicknesses were chosen to allow only moderate infiltration into the sand. The selected grain size is consistent with typical grain sizes found by martian rovers $(52 \%$ of fine-grained soil $<250 \mu \mathrm{m}$ in Gale soil $\left.^{28}\right)$. We used pure water and brine solution to create the frozen blocks. Both were made using $70 \mathrm{~g}$ of pure water. For the briny block we prepared a eutectic magnesium sulfate solution of $25 \mathrm{wt} \% \mathrm{MgSO}_{4} . \mathrm{MgSO}_{4}$ has been detected on $\mathrm{Mars}^{29}$. In solution it has an intermediate viscosity between that of water and other likely martian sulfates/chlorides ${ }^{16}$ and a eutectic temperature of $270 \mathrm{~K}^{16}$. A lamp was placed above the frozen block to simulate heating by solar illumination, and its intensity adjusted to maintain 293K. As melting on Mars likely occurs in the sub-surface, a thin cover of basalt powder was deposited on top of the frozen block to prevent excessive sublimation.

\section{Instrumentation.}

Experiments at martian atmospheric pressure were conducted in the low pressure Mars Chamber at the Open University (Milton Keynes, UK). In order to reproduce optimal conditions for liquid formation and stability on Mars, the majority of the experiments were performed at $9 \mathrm{mbar}^{14}$, and the others were performed at the mean martian pressure of 
$6.5 \mathrm{mbar}^{14}$ (Supplementary Table 1$)$. The pressure was actively controlled using a vacuum pump and recorded every 30s. We were able to control the pressure to within better than $0.5 \mathrm{mbar}$ and we observed no relationship between these small fluctuations in pressure and the observed process(es). The composition of the atmosphere in the Mars chamber is terrestrial and the humidity is thus larger than martian one. This mainly changes the evaporation rate and thus, the volume of produced liquid for a similar size of ice block ${ }^{1}$. The chamber is $1 \mathrm{~m}$ in diameter and $2 \mathrm{~m}$ long $^{12}$. Each experiment was installed at ambient pressure and temperature. In order to keep the block frozen during the 30min of depressurization, the board was placed on a cold copper plate (Supplementary Fig. 1) and the insolation only started when the selected pressure was reached. Six thermocouples were used to monitor the temperature (Supplementary Fig. 1). All experimental runs were monitored and recorded using two internal webcams and one external digital camera. The flow propagation speed was calculated by using the timestamps of the video-stills and estimating the flow propagation distance with the aid of a graduated ruler in the image frame. Once each experiment had finished, photographs were taken of the surface from different angles to produce $0.5 \mathrm{~mm} /$ pix elevation model via the "structure from motion" 30 technique using Agisoft Photoscan Professional software. A $1 \mathrm{~cm}$ moving window was used to calculate the mean elevation from the resultant Digital Elevation Model of the testbed. The volumes moved were calculated within the active area by taking the difference between this surface and the original elevation model, then summing the positive and negative values.

$$
\text { Experiments at terrestrial pressure (1bar) were conducted in the cold room at Geops }
$$
laboratory (Orsay, France) with the same setup (only the copper plate was removed). The cold room was set at $0^{\circ} \mathrm{C}$ for the preparation step. Once the isolation step was started, the room was set at $293 \mathrm{~K}$. Temperature was monitored by the cold room sensor and by one thermocouple pair located within $1 \mathrm{~cm}$ of the frozen block. Photographs were taken at regular 
intervals using a digital camera located in front of the experiments. The flow speed was estimated by using the timestamp of each photo and a direct measurement of the flow length. The volume moved in experiment 27 was calculated by measuring the area of the "gully" on an orthophoto and estimating the thickness of sediment moved. The maximum, minimum and respectively. most-likely thicknesses of erosion/deposition were assumed to be $2 \mathrm{~mm}, 1 \mathrm{~mm}$ and $1.5 \mathrm{~mm}$

\section{References:}

1. Hecht, M.H., Metastability of liquid water on Mars. Icarus, 156, 373-386 (2002).

2. Grimm, R. E., Harrison, K. P., Stillman, D. E., Water budgets of martian recurring slope lineae. Icarus 233, 316-327 (2014).

3. Brass, G.W., Stability of brines on Mars. Icarus 42, 20-28 (1980).

4. Chevrier, V.F., Rivera-Valentin, E.G., Formation of recurring slope lineae by liquid brines on present-day Mars. Geophys Res Lett 39, L21202 (2012).

5. Martinez, G. M., Renno, N. O., Water and brines on Mars: Current evidence and implication for MSL. Space Sci Rev 175, 29-51 (2013).

6. Ojha, L., et al., Spectral evidence for hydrated salts in recurring slope lineae on Mars. Nature Geoscience 8, 829-832 (2015).

7. McEwen, A. S. et al., Seasonal flows on warm Martian slopes. Science 333, 740-743 (2011).

8. McEwen, A.S. et al., Recurring slope lineae in equatorial regions of Mars. Nature Geoscience 7, 53-58 (2014).

9. Stillman, D. E., Michaels, T. I., Grimm, R. E., Harrison, K. P., New observations of martian southern mid-latitude recurring slope lineae (RSL) imply formation by freshwater surface flows. Icarus 233, 328-341 (2014). 
10. Gough, R. V., Chevrier, V. F., Baustian, K. J., Wise, M. E., Tolbert, M. A., Laboratory studies of perchlorate phase transitions: Support for metastable aqueous perchlorate solutions on Mars. EPSL 312, 371-377 (2011).

11. Kereszturi, Á., et al., Recent rheologic processes on dark polar dunes of Mars: Driven by interfacial water? Icarus 201(2), 492-503 (2009).

12. Conway, S. J., Lamb, M. P., Balme, M. R., Towner, M. C., Murray, J. B., Enhanced runout and erosion by overland flow at low-pressure and sub-freezing conditions: Experiments and application to Mars. Icarus 211, 443-457 (2011).

13. Jouannic, G., et al., Laboratory simulation of debris flows over sand dunes: Insights into gully-formation (Mars). Geomorphology 231, 101-115 (2015).

14. Haberle, R. M., et al., Preliminary interpretation of the REM pressure data from the first 100 sols of the MSL mission. JGR: Planets 119, 440-453 (2014).

15. Massé, M., et al., Spectroscopy and detectability of liquid brines on Mars. Planetary and Space Sciences 92, 136-149 (2014).

16. Chevrier, V. F., Ulrich, R., Altheide, T. S., Viscosity of liquid ferric sulfate solutions and application to the formation of gullies on Mars. JGR: Planets 114, E06001 (2009).

17. Atwood-Stone, C., McEwen, A.S., Avalanche slope angles in low-gravity environments from active Martian sand dunes. Geophysical Research Letters 40, Issue 12, pp. 2929-2934 (2013).

18. Kreslavsky, M. A., and Head, J. W., Slope streaks on Mars: a new "wet” mecanism. Icarus 201, 517-527 (2009).

19. Malin, M. C., and Edgett, K. S., Evidence for recent groundwater seepage and surface runoff on Mars. Science 288, 2330-2335 (2000).

20. Möhlmann, D., and Kereszturi, A., Viscous liquid film on dune slopes of Mars. Icarus 207, 654-658 (2010). 
21. Dundas, C. M., Diniega, S., McEwen, A. S., Long-term monitoring of martian gully formation and evolution with MRO/HiRISE. Icarus 251, 244-263 (2015).

22. Sullivan, R., Thomas, P., Veverka, J., Malin, M., Edget, K. S., Mass movement slope streaks imaged by the Mars Orbiter Camera. JGR: Planets 106(E10), 23607-23633 (2001).

23. Hansen, C. et al., Seasonal erosion and restoration of Mars' northern polar dunes. Science 331(6017), 575 (2011).

24. Chojnacki, M. et al., Active slopes of Valles Marineris - wind, water and gravity. Lunar and Planetary Science Conference, 2752 (2015).

25. Vincendon, M., Identification of Mars gully activity types associated with ice composition. JGR: Planet, 10.1002/2015JE004909 (2015).

26. Appéré, T., et al., Winter and spring evolution of northern seasonal deposits on Mars from OMEGA on Mars Exppress. JGR: Planets 116, E05001 (2011).

27. Jouannic, G. et al., Morphological and mechanical characterization of gullies in a periglacial environment: The case of the Russel crater dune (Mars). Planetary and Space Science 71, 38-54 (2014).

28. Cousin A., et al., Composition of coarse and fine particles in martian soils at gale: a window into the production of soils. Icarus 249, 22-42 (2015).

29. Gendrin, A., et al., Sulfates in Martian layered terrains: The OMEGA/ Mars Express view. Science 307, 1587-1591 (2005).

30. Westoby, M. J., Brasington, J., Glasser, N. F., Hambrey, M. J., Reynolds, J. M., ‘Structure from-Motion' photogrammetry: A low-cost, effective tool for geoscience applications. Geomorphology 179, 300-314 (2012). 
* All correspondence and requests for materials should be addressed to the corresponding author: Marion Massé, Laboratoire de Planétologie et Géodynamique, UMR 6112, CNRS, Université de Nantes, 2 chemin de la Houssinière, BP 92205, 44322 Nantes Cedex 3 (France), marion.masse@univ-nantes.fr.

\section{Acknowledgements}

This work has been funded by "Programme National de Planétologie" and by the P2IO LabEx (ANR-10-LABX-0038) in the framework "Investissements d'Avenir" (ANR-11-IDEX-000301) managed by the French National Research Agency (ANR). SJC was funded by a Leverhulme Trust Grant RPG-397. Thorough advises and help by S. Le Mouélic and O. Bourgeois greatly improved the quality of this article. We thank Wouter Marra and an anonymous reviewer for their insightful comments.

\section{Author contributions}

The methodology and experimental set-up was conceived and designed by MM, SJC and JG with significant advice, help and technical support from MP, KP, AM, VC, MB, LO, FC and GJ. All data analysis was done by MM with significant feedback from SJC, JG and KP. MV and FP provided data about current water ice location and deposition. JG, SJC and SC provided physical constrains and models. All authors contributed to discussion, interpretation and writing.

\section{Additional information}


343 The authors declare no competing financial interests.

$345 \quad$ Figures

347 Fig 1. Final morphology of flows produced on a sand thickness of 1-2mm by the melting of:

348 a) frozen water and b) frozen brine at 1 bar, $293 \mathrm{~K}$ (experiment 22 and 27, Table 1), and c)

349 frozen water and d) frozen brine at 9mbar, 293K (experiment 4 and 14, Table 1).

a) Earth: pure water

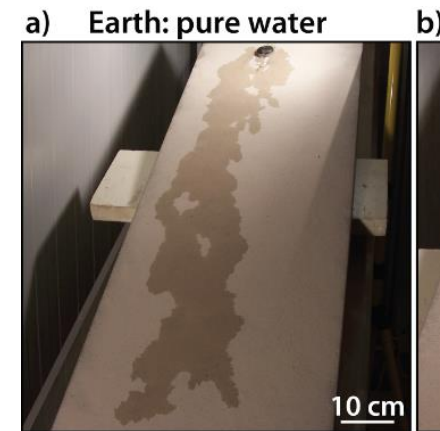

Earth: brine

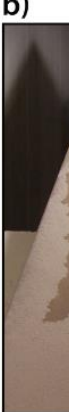

c) Mars: pure water

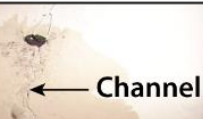

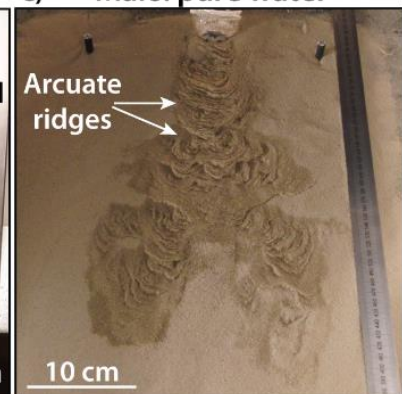

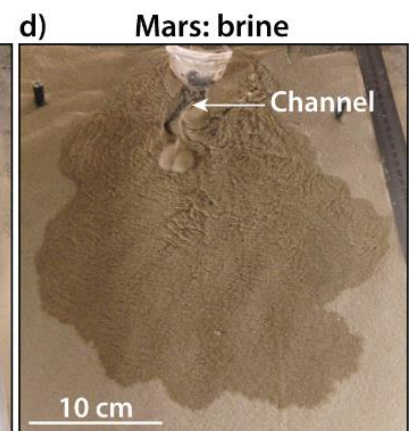


Fig 2. Impact and evolution of the flow for different pressures and ice compositions. a)

Evolution of the flowpath length with time (time is normalised by the total duration of

365

366

367

a)

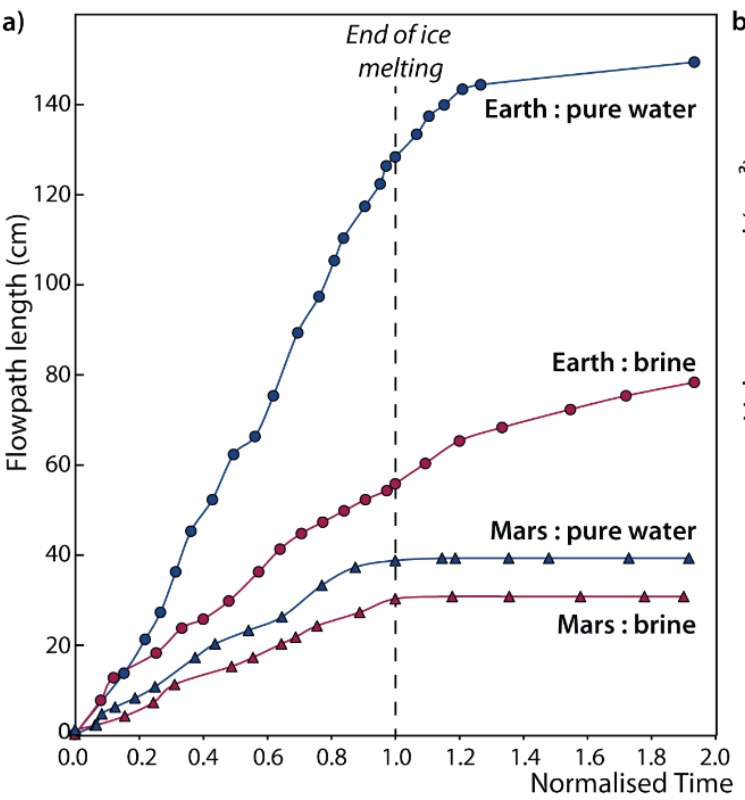
performing the volume estimate. melting) for same experiments as Fig. 1. b) Volume of sediment moved for all experiments under different conditions. The error bars were calculated by taking the difference between an interpolated reference surface and the final elevation model outside the flow and scaling-up for the area of the flow. The error bars for brines under terrestrial conditions were calculated by changing the thickness of erosion/deposition in the original calculation by $\pm 0.5 \mathrm{~mm}$ and re-

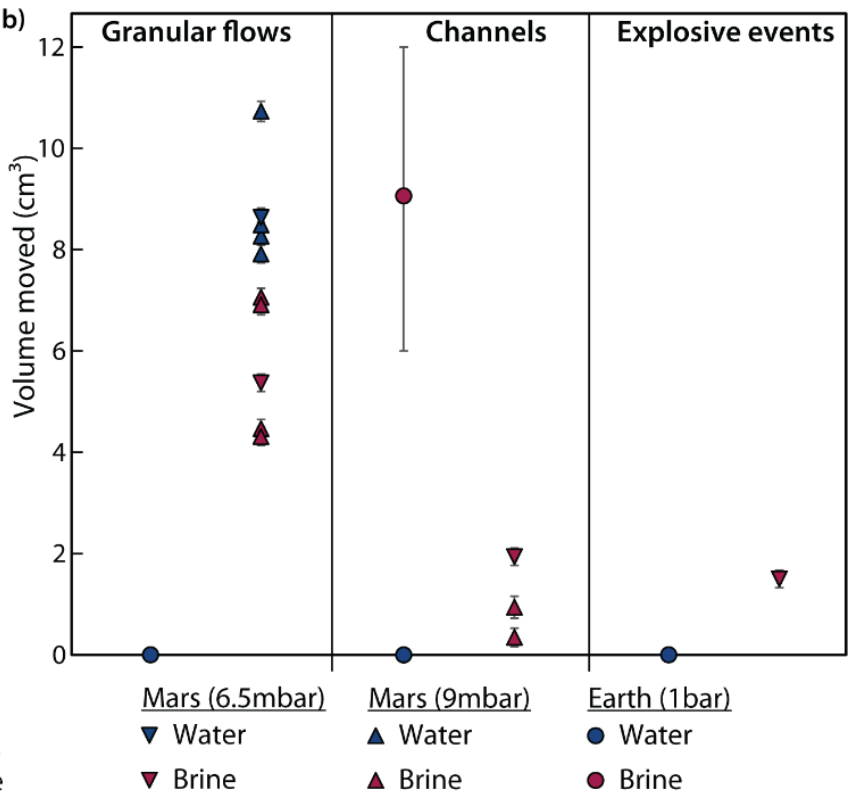


379 Fig 3. Interpretative cross-sections detailing the mechanism of liquid water propagation at martian pressure. Blue areas correspond to saturated sand where water is infiltrating and

381 yellow areas correspond to dry sand.

382

T1 Intergranular Drymaterial ejection wet flow

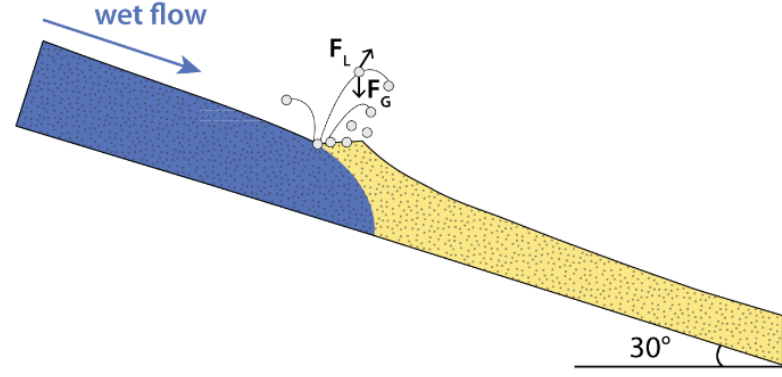

T3 Intergranular Dry granular flow (from $\theta>30^{\circ}$ )

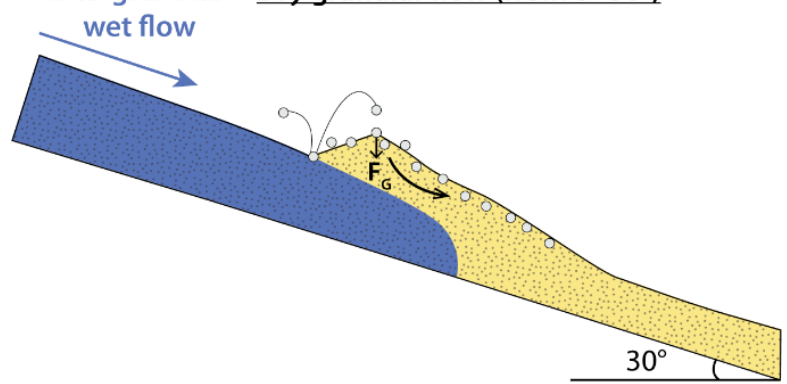

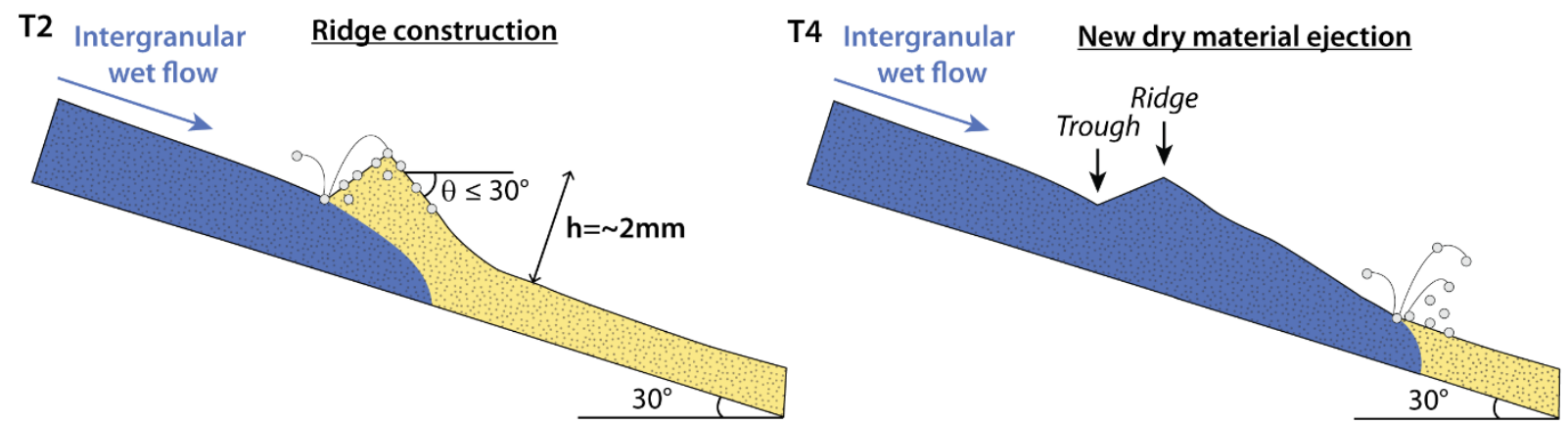

T4 Intergranular

New dry material ejection

$$
\text { wet flow }
$$


395 Fig 4. Examples of current surface changes on Mars: a) Recurring Slope Lineae (RSL)

396 (HiRISE image: ESP_022689_1380, center coordinates: $41.6^{\circ} \mathrm{S}, 202.3^{\circ} \mathrm{E}$ ), the white arrows

397 indicate smooth pale fans below the RSL, b) slope streaks (HiRISE image:

398 ESP_021527_1960, center coordinates: $15.8^{\circ} \mathrm{N}, 238.2^{\circ} \mathrm{E}$ ), c) gullies (HiRISE image:

399 ESP_027567_1425, center coordinates: $37.4^{\circ} \mathrm{S}, 22^{\circ} \mathrm{E}$ ) and d) polar dune flows (HiRISE

400 image: PSP_003386_1080, center coordinates: $\left.72^{\circ} \mathrm{S}, 179.4^{\circ} \mathrm{E}\right)$.

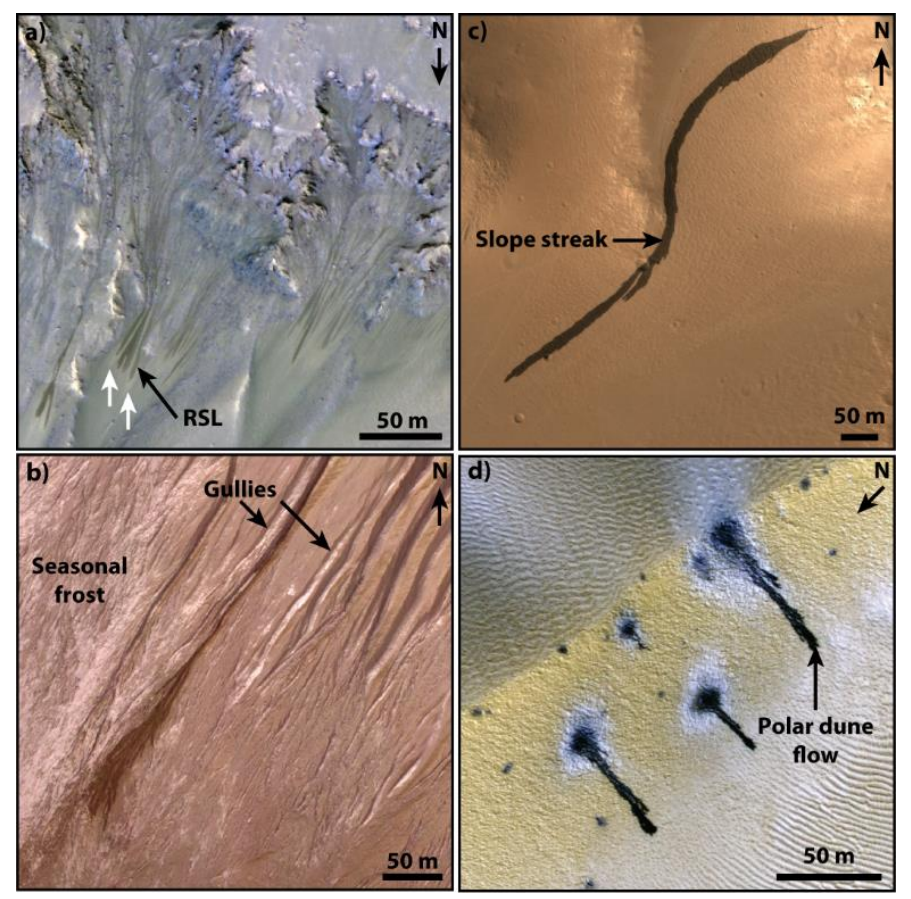




\section{Supplementary information}

\section{Supplementary Discussion}

\section{(1) Saltation by boiling}

We can split the process of grain saltation by boiling into two stages: first the initial acceleration of the sand grain induced by the boiling process, and second the ballistic trajectory for the grain which causes a downslope ridge to be built.

The process of boiling is a complex, but well-studied physical phenomenon. Treated simply, it is the conversion of a liquid into a gas, however it is more complex than evaporation, because it occurs at temperatures in excess of the boiling point (superheating), which causes the formation of bubbles, creating a multiphase (gas-liquid) fluid. In our experiments, the liquid water we produced via melting was already at the triple-point, therefore any temperature in excess of $273 \mathrm{~K}$ constitutes superheat. The liquid water was in contact with material between $288 \mathrm{~K}$ and $293 \mathrm{~K}$, corresponding to a superheat of $288-293 \mathrm{~K}$ and therefore the water was in the "nucleate" boiling regime", where gas can be released as jets or columns. In order to assess whether it is indeed these expulsions of gas which result in grain saltation, we first need to estimate the speed at which a sand grain needs to be ejected in order for it to obtain the necessary height and distance to form the ridges we observe in our experiments.

We therefore performed some simple calculations of the ballistic trajectories of the grains under terrestrial gravitational acceleration (Fig. S3). Similarly to Brož et al. (2014) $)^{2}$ this finite difference model takes into account the influence of the weight of the sand grain $\left(F_{G}=m g\right.$; Fig. 3) and the drag force exerted by the martian atmosphere $\left(F_{D}=0.5 \rho_{f} A C_{D} v^{2}\right)$, where $m$ is the mass of the sand grain, $g$ the gravity, $\rho_{f}$ the fluid density, $A$ is the surface area of the grain, $C_{D}$ is the drag coefficient and $v$ the velocity of the sand ejected. We used $C_{D}=1.18$ after de Blasio $(2011)^{3}$ and a $\rho_{f}$ of $\sim 0.01 \mathrm{~kg} . \mathrm{m}^{-3}$ calculated for our experiments using the gas law. We used an angle of projection from the horizontal $\beta$ and ejected the grains over an inclined plane with a slope of $\theta=30^{\circ}$ (matching our experimental setup). We assumed spherical grains. Next we optimized the initial grain speed so that the model produced the same morphology as the experiment, as follows. In order to obtain grain-saltation which achieves the same height and width of the ridges observed in the experiment (height $5-10 \mathrm{~mm}$, with an angle of repose at $30^{\circ}$ ), an initial grain speed of $\sim 0.35 \mathrm{~m} . \mathrm{s}^{-1}$ is required. In order to accelerate a grain to this speed, the gas velocity must be sufficient to entrain and accelerate the grain. We used the same formulation for the drag-force and constants as defined above and assumed a phase of acceleration over a distance of $1 \mathrm{~mm}$ (equivalent to the path-length assumed below), from this we obtained a gas speed of $\sim 90-100 \mathrm{~m} \cdot \mathrm{s}^{-1}$.

As stated above we believe that jets of gas produced through nucleate boiling are a logical candidate process for creating the impulsion $\left(F_{L} ;\right.$ Fig. 3$)$ which accelerates the grains. Using the work of Jolly $(2004)^{4}$ we were able to perform some simple calculations to assess whether such a mechanism could produce gas speeds approaching the required $\sim 90-100 \mathrm{~m} . \mathrm{s}^{-1}$. The work of Jolly $(2004)^{4}$ considers the theoretical framework of boiling in capillary tubes. In our case we consider the porosity of the sediment as the "tube", with a path length of $L$ through the sand layer $(e=1 \mathrm{~mm})$. We assume its cross sectional area can be approximated by the gaps between grains, where we assume a porosity of $25 \%$ to $40 \%$, giving an equivalent radius $\left(R_{e q}\right)$ of $\sim 10 \mu \mathrm{m}$. We assume that the phase change occurs because the liquid experiences a decrease in pressure along the "tube". We know that the surface of the sand is in contact with the atmosphere of the chamber $\left(P_{s}=600\right.$ or $\left.900 \mathrm{~Pa}\right)$ whereas the vapour pressure of the liquid 
in the sand layer is at $T_{0}=293 \mathrm{~K}\left(P_{l i q}>P_{s a t}\left(T_{0}\right)>P_{s}\right)$. The difference between these two pressures is given by $\delta P_{v}=P_{s a t}\left(T_{0}\right)-P_{s}$. If the equivalent radius is small enough we can assume to the first approximation that all the liquid is converted into vapour, when its pressure is less than, or equal to $P_{\text {sat }}\left(T_{0}\right)$ along the path.

Therefore, using the following formulation, we can estimate the speed of the gas $\left(U_{\text {gas }}\right)$ induced by the phase-change within the pores of the sediment:

$U_{\text {gas }}=\left(R_{e q}^{2} \delta P_{v}\right) /\left(8 L \mu_{v}\right)$

where $\mu_{v}$ is the dynamic viscosity of the gas. For $R_{e q}=7 \times 10^{-5} \mathrm{~m}, \delta P_{v}=1400 \mathrm{~Pa}$, $L=\mathrm{e} \sin \left(30^{\circ}\right)$ and for water vapour $\mu_{v}=1.8 \times 10^{-5} \mathrm{~kg} \cdot \mathrm{m}^{-3}$, we obtain a gas speed, $U_{\text {gas }}=91$ $\mathrm{m} . \mathrm{s}^{-1}$. This speed is within the range of the $90-100 \mathrm{~m} . \mathrm{s}^{-1}$ required to impart an initial velocity of $\sim 0.35 \mathrm{~m} . \mathrm{s}^{-1}$ to build ridges of the size observed in our experiments. Therefore we conclude that such a mechanism is physically plausible and that this kind of boiling is capable of inducing grain saltation.

In addition, as noted previously, in order to accelerate the grain the gas speed needs to be sufficient to overcome the weight of the grain. Therefore, this mechanism should have an upper limit on grainsize, and although we have not tested this experimentally, we can further explore this limit numerically (see below).

\section{(2) Effect of reduced martian gravity}

The difference in gravitation acceleration between our experiments and those experienced on the surface of Mars affect a number of the physical processes present in our experiments, including: fluid propagation rates, grain ejection trajectories and finally the resulting granular flows.

In order to estimate the effect of martian gravity on the grain-trajectory we have built a simple numerical model. We simulate the acceleration-stage by assuming an outgoing gas-velocity of $100 \mathrm{~m} . \mathrm{s}^{-1}$, as discussed above. This acceleration phase places limits on the grainsize that can be ejected by this process of $\sim 2 \mathrm{~mm}$ under terrestrial conditions and $\sim 4 \mathrm{~mm}$ under martian conditions (calculated for $\beta=80^{\circ}$ ).

In the boiling scheme described above, capillary forces dominate over gravitational forces, therefore the outgoing gas speed should be independent of gravitational acceleration ${ }^{4}$. However, because of the reduced gravity on Mars, the counteracting weight force $\left(F_{G}\right)$ is reduced, resulting in a higher initial grain ejection speed, compared to Earth. In our simulations we have considered grain trajectories including and excluding this effect.

After this initial acceleration, we let the grain follow a ballistic trajectory. The results of the simulation are shown for terrestrial and martian gravity on Fig. S3, the grain travels $\sim 2.5-3$ times further under martian conditions. Because of the low atmospheric density, under both terrestrial and martian gravity, the weight is significantly higher than the drag force $\left(F_{G}\right.$ $>F_{D}$ ), so the path followed by the grain is described by a quasi-parabolic curve, which is independent of the grain mass and size, for a given initial velocity.

Because the grains travel $\sim 2.5$ times further, the resulting ridge would be at least $\sim 2.5$ times wider. As observed in our experiments we expect this ridge to grow until it reaches the angle of repose and triggers a grain-flow, therefore the ridge would also be $\sim 2.5$ times higher. Therefore, such a ridge would be $\sim 3$ times more voluminous under martian gravity, resulting in ensuing granular flows with a similar increase in volume and a corresponding increase in downslope transport. As the dynamic angle of friction does not scale with gravity ${ }^{5,6}$, this 
would mean the additional runout of such flows would be simply caused by their increased volume.

As discussed in more detail in other papers ${ }^{7,8}$, gravity forces dominate over capillary forces for percolation and therefore fluid percolation rates on Mars are $~ 1 / 3$ slower than on Earth due to the reduced martian gravity. The likely result of this is that ridges built by saltation could be even larger because the boiling-front does not saturate the ridge so quickly, compensating for the reduced transport from a slower-flow propagation. This compensation effect, however would need to be confirmed in the laboratory by further simulations.

\section{(3) Up-scaling to landscape-scale}

The process of grain-saltation occurs at the interface between the saturated and dry sediment, and notably at the surface. No matter how deep the sediment, or voluminous the flow, this process should still occur at the linear interface. Therefore, even at landscape-scale we expect the ridges and associated granular flows to remain at the centimetre- to decimetre-scale, respectively, therefore approaching, but still below the present observable limits of orbital data. As an example, using our coupled acceleration-ballistic model described above, using the lowest reasonable grainsize of $50 \mu \mathrm{m}$ (the smallest size before electrostatic forces become important) and leaving the other parameters the same, we predict ridges up to $25 \mathrm{~cm}$ in width $(\sim 10 \mathrm{~cm}$ high) for martian gravity, which could result in up to metre-scale granular flows.

\section{References:}

1. Bergman, T.L., Lavine, A.S., Incropera, F.P., Dewitt, D.P., Fundamentals of Heat and Mass Transfer. 7th ed. John Wiley \& Sons (2011).

2. Brož, P., Čadek, O., Hauber, E., Rossi, A.P., Shape of scoria cones on Mars: Insights from numerical modeling of ballistic pathways. Earth and Planetary Science Letters 406, 14-23 (2014).

3. De Blasio, F.V., Landslides in Valles Marineris (Mars): A possible role of basal lubrication by sub-surface ice. Explor. Phobos 59, 1384-1392 (2011).

4. Jolly, P., Contribution à l'étude du changement de phase liquide-vapeur dans des capillaires micrométriques en vue des applications aux étanchéités statiques. PhD report, Université de Poitiers (2004).

5. Atwood-Stone, C., McEwen, A.S., Avalanche slope angles in low-gravity environments from active Martian sand dunes. Geophysical Research Letters 40, 2929-2934 (2013).

6. Kleinhans, M.G., Markies, H., de Vet, S.J., Veld, A.C., Postema, F.N., Static and dynamic angles of repose in loose granular materials under reduced gravity. Journal of Geophysical Research: Planets 116, 2011JE003865 (2011).

7. Grimm, R.E., Harrison, K.P., Stillman, D.E., Water budgets of martian recurring slope lineae. Icarus 233, 316-327 (2014).

8. Levy, J., Hydrological characteristics of recurrent slope lineae on Mars: Evidence for liquid flow through regolith and comparisons with Antarctic terrestrial analogs. Icarus 219, 1-4 (2012). 
Table S1: List and description of all the experiments performed in the Mars Chamber (Open University, UK, Experiments 1-21) and in the cold room (Geops, France, Experiments 22-31). The pressure for experiments performed in the Mars Chamber was recorded every 30 seconds and the standard deviation from the mean pressure is given for each experiment.

\begin{tabular}{|c|c|c|c|c|c|c|c|}
\hline Experiment & $\begin{array}{c}\text { Pressure } \\
\text { (mbar) }\end{array}$ & Composition & $\begin{array}{l}\text { Sand } \\
\text { thickness }\end{array}$ & $\begin{array}{c}\text { Flowpath } \\
\text { length }(\mathrm{cm})\end{array}$ & \begin{tabular}{|l|} 
Flowpath \\
maximum \\
width $(\mathrm{cm})$ \\
\end{tabular} & $\begin{array}{c}\text { Dry } \\
\text { granular } \\
\text { flows } \\
\end{array}$ & Channel \\
\hline 1 & $9.5 \pm 0.53$ & Pure water & $1-2 \mathrm{~mm}$ & 42.5 & 26 & Yes & No \\
\hline 2 & $9.8 \pm 0.19$ & Pure water & $1-2 \mathrm{~mm}$ & 35.5 & 24 & Yes & No \\
\hline 3 & $9.6 \pm 0.30$ & Pure water & $1-2 \mathrm{~mm}$ & 44.5 & 27 & Yes & No \\
\hline 4 & $9.6 \pm 0.12$ & Pure water & $1-2 \mathrm{~mm}$ & 39 & 22.5 & Yes & No \\
\hline 5 & $9.7 \pm 0.22$ & Pure water & $1-2 \mathrm{~mm}$ & 48 & 23 & Yes & No \\
\hline 6 & $9.8 \pm 0.12$ & Pure water & $1-2 \mathrm{~mm}$ & 32 & 27 & Yes & No \\
\hline 7 & $6.8 \pm 0.20$ & Pure water & $1-2 \mathrm{~mm}$ & 25 & 21 & Yes & No \\
\hline 8 & $29.3 \pm 0.45$ & Pure water & $1-2 \mathrm{~mm}$ & 45 & 26 & No & No \\
\hline 9 & $9.7 \pm 0.13$ & Pure water & 3-4 mm & 32 & 21 & Yes & No \\
\hline 10 & $9.6 \pm 0.17$ & Pure water & 3-4 mm & 31 & 16 & Yes & No \\
\hline 11 & $9.7 \pm 0.10$ & Pure water & 3-4 mm & 33 & 16 & Yes & No \\
\hline 12 & $9.7 \pm 0.11$ & Pure water & 3-4 mm & 31 & 14 & Yes & No \\
\hline 13 & $9.6 \pm 0.12$ & Brine & $1-2 \mathrm{~mm}$ & 37 & 36 & Yes & No \\
\hline 14 & $9.7 \pm 0.17$ & Brine & $1-2 \mathrm{~mm}$ & 33 & 24 & Yes & Yes \\
\hline 15 & $9.3 \pm 0.41$ & Brine & $1-2 \mathrm{~mm}$ & 36 & 24 & Yes & Yes \\
\hline 16 & $9.7 \pm 0.16$ & Brine & $1-2 \mathrm{~mm}$ & 40 & 25 & Yes & Yes \\
\hline 17 & $6.8 \pm 0.21$ & Brine & $1-2 \mathrm{~mm}$ & 25 & 22 & Yes & Yes \\
\hline 18 & $9.6 \pm 0.09$ & Brine & 3-4 mm & 24 & 21.5 & Yes & Yes \\
\hline 19 & $9.6 \pm 0.10$ & Brine & 3-4 mm & 22 & 23 & Yes & No \\
\hline 20 & $9.6 \pm 0.12$ & Brine & 3-4 mm & 24 & 21 & Yes & No \\
\hline 21 & $9.8 \pm 0.21$ & Brine & 3-4 mm & 22 & 17 & Yes & No \\
\hline 22 & 1000 & Pure water & $1-2 \mathrm{~mm}$ & 149 & 20 & No & No \\
\hline 23 & 1000 & Pure water & $1-2 \mathrm{~mm}$ & 150 & 23 & No & No \\
\hline 24 & 1000 & Pure water & $1-2 \mathrm{~mm}$ & 101 & 22 & No & No \\
\hline 25 & 1000 & Pure water & 3-4 mm & 63.5 & 15 & No & No \\
\hline 26 & 1000 & Pure water & 3-4 mm & 67.5 & 21 & No & No \\
\hline 27 & 1000 & Brine & $1-2 \mathrm{~mm}$ & 83 & 35 & No & Yes \\
\hline 28 & 1000 & Brine & $1-2 \mathrm{~mm}$ & 83 & 38 & No & Yes \\
\hline 29 & 1000 & Brine & $1-2 \mathrm{~mm}$ & 90.5 & 28 & No & No \\
\hline 30 & 1000 & Brine & 3-4 mm & 67 & 18 & No & No \\
\hline 31 & 1000 & Brine & 3-4 mm & 73.5 & 22 & No & No \\
\hline
\end{tabular}




\section{Supplementary figures:}

145

146 Figure S1: The experimental setup. a) Diagram of the experimental setup. The points C 147 represent the emplacement of all the thermocouples. b) Picture of the Martian Chamber (Open 148 University, UK).
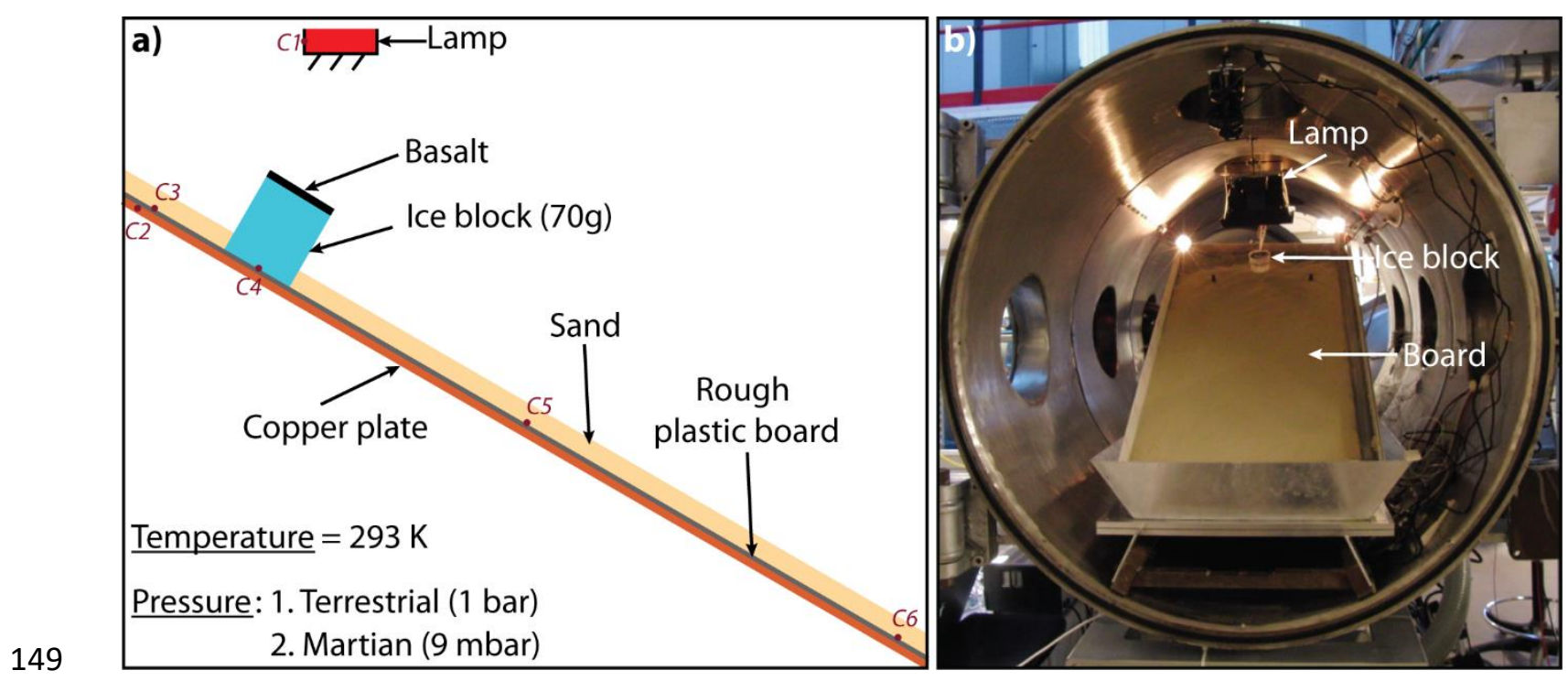
151

152

153

154

Figure S2: Hillshaded digital elevation models with overlain difference maps (see Methods) of the final morphologies obtained for the experiments $6,7,9,11,12,15,17,18,19$ and 21 (description of the experiments on Supplementary Table 1). Colors are shown only in areas which were used to calculate volumes in Fig. $2 b$.

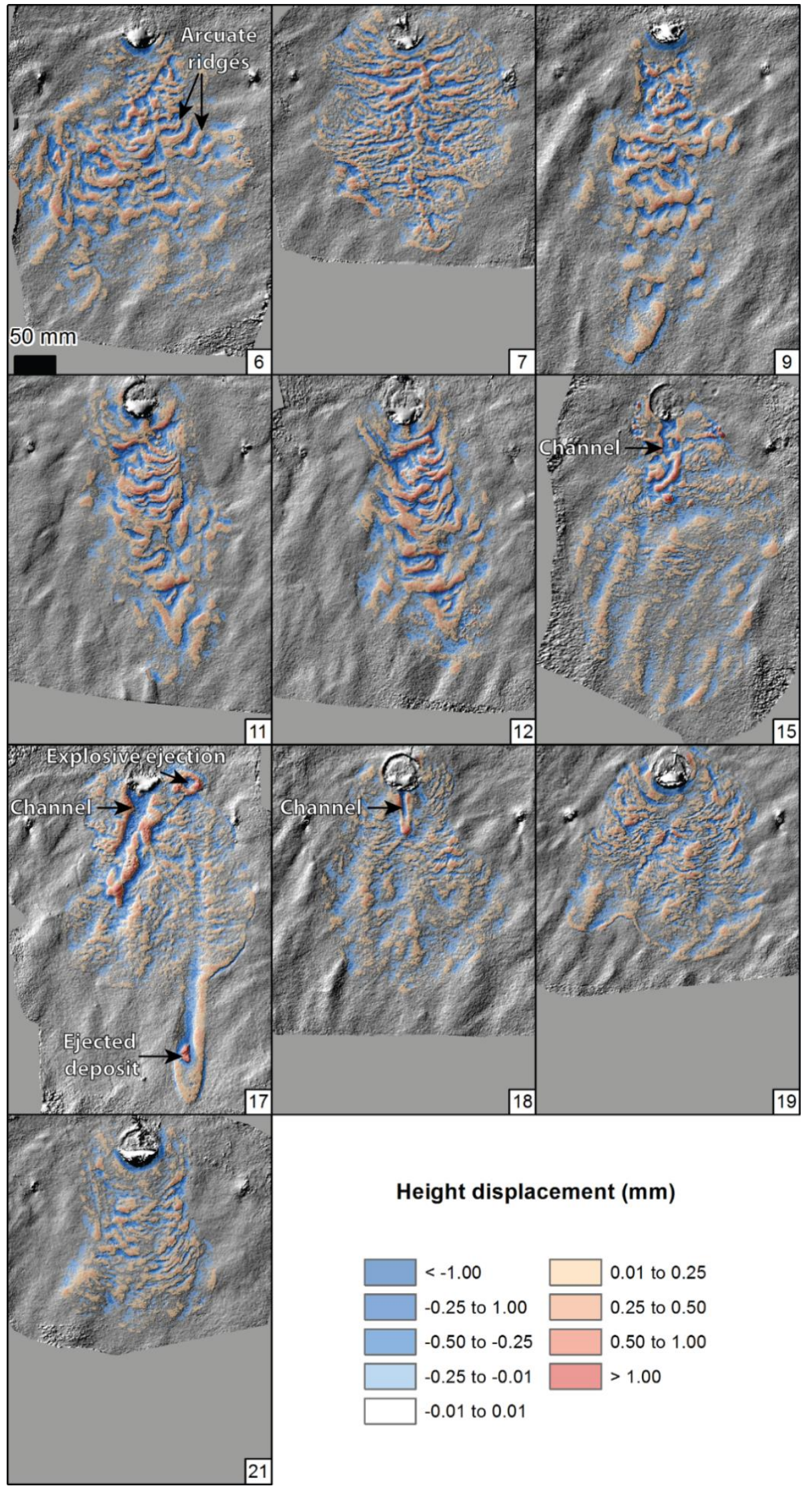


Figure S3: Saltation trajectories for $200 \mu \mathrm{m}$ grains with a density of $2600 \mathrm{~kg} \cdot \mathrm{m}^{3}$ through an atmosphere with a density of $\sim 0.01 \mathrm{~kg} . \mathrm{m}^{-3}$ under terrestrial and martian gravitational acceleration. a) Simulated trajectories using a constant initial speed of $0.365 \mathrm{~m} \cdot \mathrm{s}^{-1}$. b) Simulated trajectories using an initial speed which depends on the acceleration phase, for Earth this results in an initial speed of $0.365 \mathrm{~m} . \mathrm{s}^{-1}$, and for Mars $0.381 \mathrm{~m} . \mathrm{s}^{-1}$.
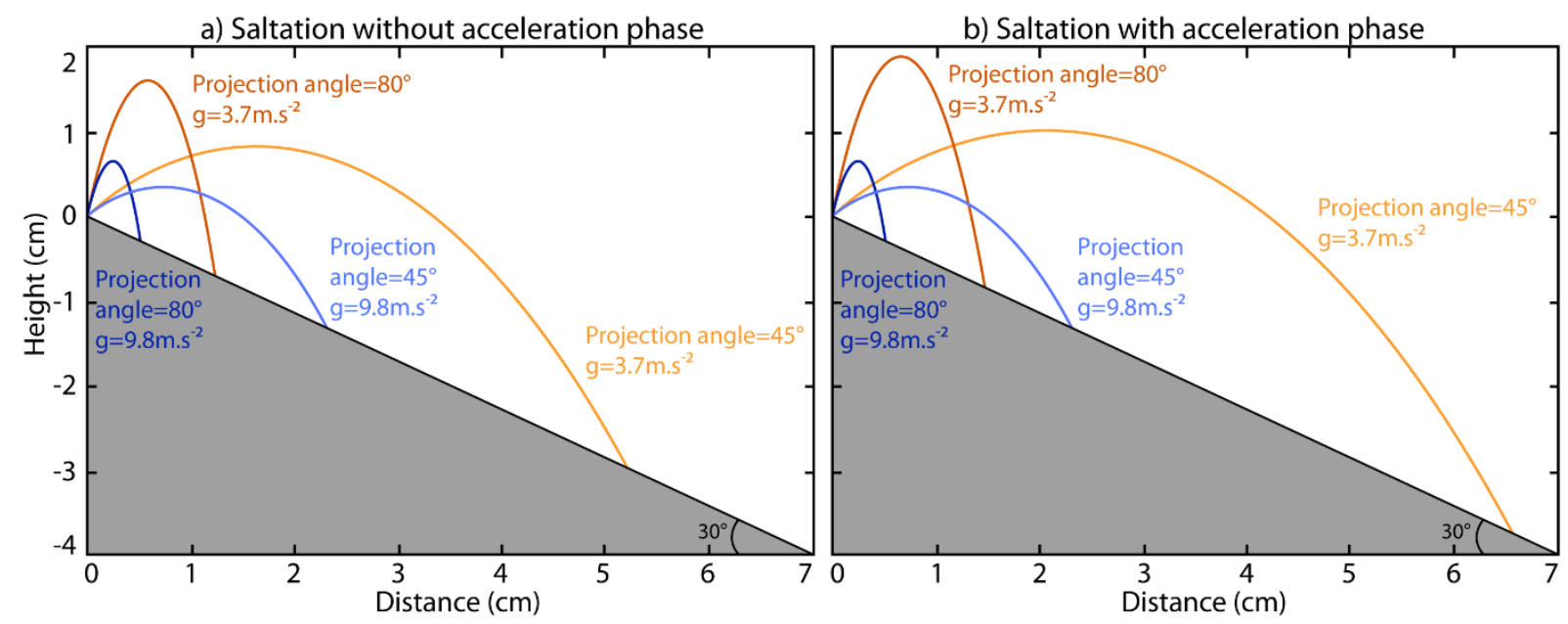


\section{Supplementary videos:}

Video S1: Movie of a flow produced by pure water ice melting at $9 \mathrm{mbar}, 293 \mathrm{~K}$ and a sand thickness of 1-2mm (experiment 2, Table 1). Boiling water is observed at the front of the flow (associated with saltation of sand grains) and at the top of the ice block.

Video S2: Movie of a flow produced by pure water ice melting at $9 \mathrm{mbar}, 293 \mathrm{~K}$ and a sand thickness of 1-2mm (experiment 2, Table 1). Production of dry granular flows induced by saltation of sand grains at the front of the flow.

Video S3: Movie of a flow produced by water ice melting at $6.5 \mathrm{mbar}, 293 \mathrm{~K}$ and a sand thickness of 1-2mm (experiment 7, Table 1). Vigorous boiling is observed at the front of the flow (associated with sand grain saltation) and at the top of the ice block.

Video S4: Movie of a flow produced by briny ice melting at $6.5 \mathrm{mbar}, 293 \mathrm{~K}$ and a sand thickness of 1-2mm (experiment 17, Table 1). A briny flow starts under the sand and lifts the sand surface. An explosive ejection of saturated sediment, which is associated with the formation of a channel, occurs when the liquid brine reaches the surface (at 10 seconds). The hole produced by a previous ejection can be seen in the upper right.

Video S5: Movie of a flow produced by pure water ice melting at $9 \mathrm{mbar}, 293 \mathrm{~K}$ and a sand thickness of 3-4mm (experiment 10, Table 1). Overview of the flow evolution with time showing large dry granular flows (up to $15 \mathrm{~cm}$ long) and the formation of a series of arcuate ridges and troughs.

Video S6: Movie of a flow produced by briny ice melting at 9mbar, $293 \mathrm{~K}$ and a sand thickness of 3-4mm (experiment 18, Table 1). Overview of the flow evolution with time, showing small dry granular flows $(1-3 \mathrm{~cm}$ long, from 09:34:29 to 09:40:49) and formation of a channel (5 cm long, at 09:44:28). 